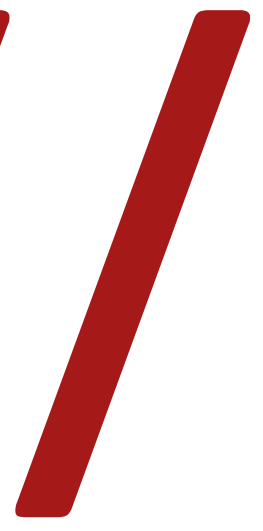

\title{
A escola francesa de som direto: Jean-Pierre Ruh e Éric Rohmer
}

French school of direct sound: Jean-Pierre Ruh and Éric Rohmer

Sérgio Puccini ${ }^{1}$

${ }^{1}$ Professor adjunto do Bacharelado em Cinema e Audiovisual, do Programa de Pós-Graduação em Artes, Cultura e Linguagens do Instituto de Artes e Design da UFJF e do International Master in Cinema Studies - IMACS/ PPGACL. Graduado em Artes Plásticas pela Universidade Estadual de Campinas, é mestre e doutor em Multimeios pela Universidade Estadual de Campinas. E-mail: sergio.puccini@ufjf.edu.br 
Resumo: O artigo trata de um dos mais destacados representantes da escola francesa de som direto, o técnico Jean-Pierre Ruh, a partir de seu trabalho com o cineasta Éric Rohmer nos filmes Ma nuit chez Maud (Minha noite com ela, 1969), Le genou de Claire (O joelho de Claire, 1970) e L'amour l'après-midi (Um amor à tarde, 1972). Tendo como principal base os depoimentos do próprio Jean-Pierre Ruh, pretendemos focar em questões caras à escola do som direto, principalmente no que tange aos sons fora de campo, às imperfeições de som, e aos sons ordinários, entendidas dentro de uma concepção que valoriza uma verdade e uma singularidade do som no filme. Observou-se que cada filme possui uma particularidade própria, assim como um som único, e todos exploram as vozes sempre projetadas no espaço, fechado ou aberto, o que acrescenta uma informação de perspectiva e profundidade.

Palavras-chave: som; som direto; Jean-Pierre Ruh; Éric Rohmer.

Abstract: The article focuses on one of the most prominent representatives of the French direct sound school, the technician Jean-Pierre Ruh, from his work with the filmmaker Éric Rohmer in the films Ma nuit chez Maud (My night at Maud's, 1969), Le genou de Claire (Claire's knee, 1970) and L'amour l'après-midi (Chloe in the afternoon, 1972). Based on testimonies by Jean-Pierre Ruh himself, we intend to focus on key issues for the direct sound school, especially with regard to the exploration of the off-screen sounds, sound imperfections, and the ordinary sounds, understood within a conception that values a truth and a singularity of the sound in the film. We observed that each movie has its own particularity and its unique sound, and all of them explore the voices projected into the space, open or closed, which adds a perspective and depth information.

Keywords: sound; direct sound; Jean-Pierre Ruh; Éric Rohmer. 


\section{Introdução}

Este artigo é desdobramento de um projeto de pesquisa que teve como foco o técnico de som francês Antoine Bonfanti². Estudos dedicados às técnicas e tecnologia do cinema têm sido mais frequentes no campo ligado à historiografia como atestam os trabalhos em torno da associação de pesquisadores Technès, coordenada por André Gaudreault (Universidade de Montreal), Gilles Mouëllic (Universidade de Rennes 2) e Laurent Le Forestier (Universidade de Lausanne). Nosso interesse é enfocar o trabalho daqueles que se utilizam das técnicas e tecnologias do cinema, os profissionais técnicos, figuras muitas vezes anônimas dentro dos estudos e das críticas de cinema. Nossa abordagem enfatiza aspectos ligados ao processo de criação e como o repertório e a concepção de trabalho desses técnicos contribui para a forma final do filme. Assim, entendemos o profissional técnico também como um profissional de criação.

Neste artigo, abordaremos o trabalho do destacado técnico de som direto francês Jean-Pierre Ruh, falecido em 2006. Mais especificamente, iremos nos deter na sua relação com o cineasta Éric Rohmer. No que concerne aos objetivos deste artigo, vamos nos ater a três filmes, da lista de cinco, envolvendo Jean-Pierre Ruh e Éric Rohmer. São eles: Ma nuit chez Maud (Minha noite com ela, 1969), Le genou de Claire (O joelho de Claire, 1970) e L'amour l'après-midi (Um amor à tarde, 1972), de Éric Rohmer.

Como um dos integrantes da nouvelle vague francesa, Éric Rohmer é um cineasta já bastante estudado, tema de inúmeros artigos, teses, biografias e análises críticas de sua extensa obra ${ }^{3}$. Só para ficarmos nos estudos mais recentes publicados no Brasil, podemos citar o artigo de Luíza Alvim (2018), Performances musicais em filmes de Rohmer, Truffaut e Godard dos anos 60, a dissertação de mestrado de Alexandre Rafael Garcia (2019), Contos morais e o cinema de Éric Rohmer, defendida no Programa de Pós-Graduação em Multimeios/Unicamp e posteriormente publicada como livro, além de um paper de Marina Takami (2013), Comentários sobre o som na obra de Éric Rohmer, apresentado no XVI Encontro da Socine (Sociedade Brasileira de Estudos de Cinema e Audiovisual), em 2012. Esses três trabalhos possuem em comum o fato de darem algum destaque para técnicos de som direto

\footnotetext{
${ }^{2}$ Pesquisa desenvolvida como estágio de pós-doutorado, junto à Universidade Sorbonne Nouvelle - Paris 3 , entre 2015 e 2016, em que estudamos o trabalho de Antoine Bonfanti em documentário. Essa pesquisa contou com financiamento da Fapemig.

${ }^{3}$ Uma consulta em sites como Theses.Fr (https://bit.ly/34qJ2Wn) ou da Biblioteca da Cinemateca Francesa (https://bit.ly/33dQQKB) dão uma boa dimensão dos trabalhos já publicados sobre o cineasta.
} 
(Jean-Pierre Ruh, Pascal Ribier e Georges Prat). No entanto, os nomes aparecem sempre como periféricos, uma vez que o interesse central dos estudos vem a ser o cineasta Rohmer. A proposta deste artigo é justamente trazer para o primeiro plano de interesse as ideias e concepções sobre som de Jean-Pierre Ruh. Nossa intenção é evidenciar aspectos caros às técnicas do som direto, como o trabalho do som fora de campo, as imperfeições de som, e a valorização daquilo que chamaremos aqui de sons ordinários ${ }^{4}$, sons que habitam um espaço periférico da faixa sonora, oriundos da abertura do microfone para o mundo, e que aparentemente não possuem grande importância na composição estética e narrativa do filme. Em torno de tudo isso, está uma concepção de som que valoriza o aspecto realista, de uma verdade contrária à limpeza e inteligibilidade de outras escolas de som, como a escola americana.

Os três filmes escolhidos para análise são marcados por cenas de conversa, uma das principais características da filmografia de Rohmer. Nessas cenas, temos uma grande variação do número de pessoas envolvidas, sendo mais comuns cenas que envolvem apenas duas pessoas. Em Ma nuit chez Maud, nos concentraremos no trabalho da captação das vozes em off e da questão da perspectiva espacial estabelecida pelo som na relação com a imagem, fruto direto do modo de captação sonora escolhido por Ruh. Em Le genou de Claire, a análise se deterá na questão dos ruídos de fundo, a ambiência e os sons ordinários que invadem a tomada, sinalizando uma abertura para o mundo via captação do som pelo microfone. Por fim, em L'amour l'après-midi, voltaremos a analisar a captação da voz, mas dessa vez, atentos a sons produzidos pela boca, ruídos mínimos que possuem importância central para Jean-Pierre Ruh. Com isso, buscamos também ressaltar não apenas as semelhanças, mas também as diferenças de som nos três filmes, obtidas graças a uma variação no trabalho de captação e mixagem.

\section{Jean-Pierre Ruh e a escola francesa de som direto}

Seguindo uma tradição que se inicia já nos primórdios do cinema sonoro, com Jean Renoir, Marcel Pagnol e Julien Duvivier (BARNIER, 2011)5, a escola francesa de som direto ganha novo impulso nos anos 1960 graças ao surgimento

\footnotetext{
${ }^{4}$ Michel Chion chama de sons-em-si, conceito próximo do que estamos chamando de sons ordinários, que se originam de intrusões do acaso, na captação de som direto, "que não estão integrados na trama narrativa e que começam a existir por si mesmos" (CHION, 2011, p. 87).

${ }^{5}$ Vale lembrar que até os anos 1950, a captação de som utilizava suporte ótico, que exigia a presença de um caminhão de som para a captação em ambientes externos. Sobre esse assunto ver, por exemplo: Barnier (2011); Souza (2010).
} 
dos gravadores magnéticos portáteis, advento que marca uma nova produção de documentários e terá impacto nos filmes de ficção do período ${ }^{6}$. Na França, essa escola terá em Antoine Bonfanti um de seus mais conhecidos representantes. Um dos campos de forte atuação de Bonfanti foi justamente o da formação de novos técnicos de som, graças aos inúmeros cursos que ministrou ao longo de sua vida (PUCCINI, 2017; PUCCINI, 2020). Segundo as palavras do próprio Bonfanti (PIMENTEL; VASCONCELOS, 1985), Jean-Pierre Ruh veio a ser um dos técnicos que ele ajudou a formar e que teria destacada carreira como técnico de som direto, sendo um dos mais radicais defensores da prática. Diz Ruh:

A escola de som direto é francesa, começou com Antoine Bonfanti. Seguiram Bernard Aubouy, Pierre Gamet e Pierre Lenoir, eu mesmo. Nós adquirimos nesse campo um conhecimento, uma desenvoltura. A técnica e as ferramentas são simples. Basta dominar o vento, a chuva, trabalhar muito depressa, encontrar microfones correspondentes às dificuldades técnicas, manter-se coerente com o quadro imagem, ser inteligível, saber jogar com os sons e os ruídos úteis e inúteis. Devemos apagar passos, rumores que perturbam. (SEGURA; MOURIÈS, 2005, p. 41, tradução nossa) ${ }^{7}$

Formado pela École Française de Radioélectricité (EFR), atualmente Efrei (École dinngénieur généraliste en informatique et technologies du numérique), Jean-Pierre Ruh iniciou sua carreira profissional em som trabalhando na Pathé-Actualités, entre 1966 e 1969. Para Ruh, o trabalho em reportagens seria fundamental em sua formação, o que, segundo ele, representou "Uma abertura extraordinária para a vida e para o mundo.” (BRISSON, 1984, p. 26, tradução nossa). Ruh também fundou, em 1973, a sociedade Elison, especializada em pós-produção sonora, além de oferecer aluguel de equipamentos de som (BRESCHAND; MORRISSEY, 2006). Além da carreira profissional no cinema, Jean-Pierre Ruh atuou ativamente em atividades de ensino, seguindo a trajetória de Antoine Bonfanti, tendo ministrado cursos nas escolas Louis Lumière, La Fémis (École Nationale Supérieure des Métiers de l-Image et du Son), assim como na Escola Internacional de Cinema e Televisão (Escuela Internacional de Cine y TV - EICTV) em Cuba.

Ao longo de mais de trinta anos de carreira, Jean-Pierre Ruh se destacou entre os nomes dos técnicos de som direto, campo a que dedicou integralmente seu trabalho.

\footnotetext{
${ }^{6}$ Sobre esse assunto ver Marie (2013), artigo em que o autor apresenta um panorama da utilização do som direto nos filmes de ficção franceses dos anos 1960, partindo do seu contato com os canadenses.

${ }^{7}$ Todas as traduções apresentadas neste artigo foram feitas pelo autor.
} 
Entre os vários diretores com quem trabalhou, destacam-se Alain Resnais, Michelangelo Antonioni, Wim Wenders, Jean Eustache, Philippe Garrel, Roman Polanski, Jean-Luc Godard, François Truffaut, Andrzej Wajda, Jean-Jacques Beineix, Claude Lelouch, Sergio Leone. De todos, Jean-Pierre encontrou em Marco Ferreri uma de suas parcerias mais duradouras, tendo com ele realizado onze filmes, parceria que se inicia com La grande bouffe (A comilança, 1973), de Marco Ferreri, cuja gravação do som foi ainda em sistema óptico de $35 \mathrm{~mm}$, posto que Ferreri ainda desconfiava do gravador magnético Nagra (BRESCHAND, MORRISSEY, 2006).

\section{Jean-Pierre Ruh e Éric Rohmer}

Para Ruh, no entanto, o encontro com Éric Rohmer para a realização de Ma nuit chez Maud seria o momento mais decisivo em sua trajetória profissional: "foi em torno desse filme que toda a minha carreira se orientou já que me tornei um incondicional do som direto" (HERPE, 2007, tradução nossa), diz Jean-Pierre Ruh.

O som direto foi uma revelação para Rohmer e para mim, notadamente naquilo que concerne a importância dos sons off. [...] Ao contrário do que dizem, a nouvelle vague e Godard não abraçaram tanto assim o som direto; foi Rohmer quem percebeu tudo aquilo que poderíamos fazer, com tudo o que implica de imperfeições, com as respirações, os fundos de ambiência, a acústica do lugar. (HERPE, 2007, tradução nossa)

Ainda, segundo Ruh:

Rohmer foi o primeiro que soube compreender a riqueza do som direto e admitir também suas restrições técnicas. Fazer o som direto não significa nada se o diretor não compreender que é necessário pensar, antes mesmo da filmagem, que ele deve preparar a banda sonora da mesma maneira como ele prepara a decupagem das imagens tanto no que se refere ao trabalho com os atores como também dos espaços de filmagem. (BRISSON, 1984, p. 26, tradução nossa)

A parceria entre Éric Rohmer e Jean-Pierre Ruh se estendeu por cinco filmes ao longo de quase dez anos: Ma nuit chez Maud (Minha noite com ela, 1969), Le genou de Claire (O joelho de Claire, 1970), L'amour l'après-midi (Um amor à tarde, 1972), Die Marquise von O... (A Marquesa d'O, 1976), Perceval le gallois (Perceval, o galês, 1978), de Éric Rohmer. Após Perceval, Rohmer passa a contar com o técnico Georges Prat, que costumava trabalhar com Jean-Pierre Ruh com regularidade, fazendo parte da mesma escola de som. No entender de Ruh, Rohmer quis experimentar 
a alternância da equipe técnica a fim de evitar um certo acomodamento que pode resultar de uma longa convivência de trabalho (HERPE, 2007) . $^{8}$

\section{Ma nuit chez Maud}

Ma nuit chez Maud é o terceiro filme da série de seis contos morais de Rohmer (o quarto a ser filmado ${ }^{9}$ ). O filme gira em torno de Jean-Louis, interpretado por Jean-Louis Trintignant, recém-chegado à cidade de Clermont, onde trabalha como engenheiro da Michelin. Católico praticante, aos poucos Jean-Louis vai se ambientando à cidade. Um de seus primeiros encontros é com a jovem Françoise, com quem flerta discretamente durante uma missa. A partir desse encontro, Jean-Louis estabelece como objetivo de vida se casar com Françoise, objetivo que orientará toda a sua conduta ao longo do filme. Como católico, Jean-Louis possui fortes convicções morais que giram em torno do casamento e da fidelidade entre o casal. Essa convicção vai ser posta à prova quando ele conhece Maud, interpretada pela atriz Françoise Fabian, amiga de seu amigo Vidal (Antoine Vitez), com quem havia se encontrado por acaso em um bar. Jean-Louis resiste ao assédio de Maud. Porém, os dois acabam desenvolvendo uma breve relação de amizade. Após deixar o apartamento de Maud, Jean-Louis reencontra Françoise ao acaso na rua, toma a iniciativa de se aproximar dela e a partir daí os dois iniciam a relação que vai resultar em um casamento e em um filho, conforme nos informa a cena final do filme.

Ma nuit chez Maud é um filme centrado na voz e na palavra, característica presente em boa parte da filmografia de Rohmer, como disse ele mesmo, os personagens estão sempre “intoxicados pelas palavras” (HANDYSIDE, 2013, p. 68, tradução nossa). As principais cenas do filme são cenas de conversa e, em sua maioria, cenas que se passam em ambientes internos. As cenas externas, que poderiam render maiores problemas para a captação do som, são cenas curtas. A sequência principal e a mais longa, a ocupar quarenta dos cento e cinco minutos do filme, é a que se passa no apartamento de Maud envolvendo Jean-Louis, Vidal e a própria Maud. A sequência é formada por duas cenas, sendo a mais longa a que se passa no período noturno e a mais curta, a que se passa na manhã do dia seguinte. No que diz respeito ao tratamento sonoro do filme, observa-se uma relação bastante harmoniosa estabelecida nos cortes entre os planos de som e imagem, muito em função do cuidadoso trabalho feito na mixagem, assinada por

\footnotetext{
${ }^{8}$ Segundo Antoine de Baecque e Noël Herpe (2016), uma das possíveis razões para a troca foi o fato de Jean-Pierre Ruh fumar demasiadamente no set.

${ }^{9}$ Ver filmografia.
} 
outro conhecido técnico de som francês, Jacques Maumont. Nos ambientes internos, os ruídos de fundo são bastante discretos ou nem existem. Uma das razões para isso vem a ser o fato de a cena mais longa do filme, a do apartamento de Maud, ter sido filmada em um estúdio. Ou, como afirma o próprio Ruh:

\begin{abstract}
Não era propriamente um estúdio, era (ao lado da rua Mouffetard) um antigo estúdio que havia sofrido um incêndio e que não era completamente insonorizado: nós fizemos um tratamento rápido no primeiro dia, Almendros para a iluminação e eu para o som - com uma cobertura acústica, já que eu queria uma acústica um pouco quente e não reverberada... Mas nós escutávamos os rumores e perturbações que vinham da rua Pot-de-fer, o que somou um pouco além do aspecto higiênico e "clean" de um estúdio hermeticamente isolado. (HERPE, 2007, tradução nossa)
\end{abstract}

Segundo Baecque e Herpe (2016), a intenção, ao construir o cenário do apartamento de Maud em um estúdio, era a de buscar o ambiente de total silêncio e de tentar compor o apartamento seguindo uma concepção esteticamente rigorosa e asséptica, dominada pelo branco. Ainda segundo Baecque e Herpe: “Antes de se envolver na aposta do plano único, ele [Rohmer] passava horas distribuindo esse ou aquele objeto, resmungando consigo mesmo o tempo todo" (2016, p. 233, tradução nossa).

Um aspecto essencial nos procedimentos de filmagem adotados por Rohmer para as cenas de conversa vem a ser a valorização dos sons fora de campo, ou sons off. Ao contrário do que seria padrão na cartilha do cinema clássico, não vemos a preocupação de cobrir, com a respectiva imagem, a voz de quem fala a todo momento. A valorização das vozes fora de campo faz com que o filme trabalhe as relações espaciais estabelecidas entre som e imagem, posto que a voz em off também carrega informações do espaço em que é emitida através das reverberações do som. Diz Ruh:

Em Ma nuit chez Maud uma grande parte do texto de Vitez e Trintignant é em off: nós não os vemos na imagem e nós os ouvimos a partir de um plano sonoro coerente em relação àquilo que vemos na imagem. (SAADA; OSTRIA, 1988, p. 85, tradução nossa)

Esse aspecto de coerência, comentado por Ruh, se relaciona à profundidade do som da voz, que informa sua localização espacial através dos efeitos de reverberação e volume, estando mais próxima ou mais distante daquilo que temos no quadro imagem. Em alguns momentos, essas relações nem sempre correspondem precisamente àquelas estabelecidas na imagem, o que diz muito sobre aquelas imperfeições implicadas na 
captação em som direto. Se nos planos de imagem percebemos uma perspectiva espacial mais controlada e estável, lembrando que o trabalho de câmera é sempre feito com o uso de tripé, nos planos de som essa perspectiva passa por um processo de modulações, criando uma variação de profundidade entre as vozes no espaço. Essa variação ocorre em função da forma de captação do som escolhida por Ruh, feita pelos chamados microfones aéreos, direcionais, sustentados pelo operador de boom, e não por microfones de lapela que ainda não eram tão comuns na época. Uma das cenas que melhor evidencia isso vem a ser a do primeiro encontro entre JeanLouis e Vidal no bar Le Suffren. Os dois conversam sentados ao redor de uma pequena mesa, portanto bastante próximos um do outro. A cena é decupada em dez planos. Todo diálogo é marcado por falas longas com poucas trocas entre os dois. Ao fundo, ouvimos o ruído das conversas no entorno e do manuseio dos pratos e talheres. Dos dez planos, cinco possuem vozes em off. A voz que permanece por mais tempo no espaço fora de campo é a de Vidal. Pela voz de Vidal, percebe-se nitidamente uma modulação da distância entre os dois no espaço sonoro: ora a voz de Vidal está mais próxima, em volume mais alto, ora bem mais distante, em volume mais baixo e mais reverberada no ambiente. No entanto, essas variações ocorrem apenas em falas rápidas e interjeições, e são assumidas pelo trabalho de captação de som.

Essa modulação da perspectiva espacial pelo som também pode ser observada em alguns momentos da sequência mais longa do filme, a que se passa dentro do apartamento de Maud, especialmente em seu início. Essa cena, que envolve Maud, Jean-Louis e Vidal, apresenta uma maior movimentação dos atores, no espaço do apartamento, e também dos planos de imagem, através do recurso de Pan horizontais e verticais, posto que, como já dissemos, o trabalho é feito com a câmera fixa no tripé. Como som de fundo, ouvimos sutilmente o som do tráfego da rua no início e no final da cena. Conforme comentado por Jean-Pierre Ruh, trata-se da rua Pot-de-fer, em Paris, situada perto do estúdio de filmagem utilizado por Rohmer. A sequência do apartamento de Maud pode ser dividida em duas cenas, contendo cinco momentos distintos. No primeiro vemos a chegada de Jean-Louis e Vidal e as conversas iniciais de apresentação com Maud. O segundo momento é quando os três passam a uma mesa para jantar, e conversam sobre o cristianismo e Pascal. O terceiro é o pós-jantar, em que os três deixam a mesa para ocupar outros espaços da sala. O quarto momento é marcado pela saída de cena de Vidal, ficando enfim Jean-Louis e Maud sozinhos. O quinto momento, que forma a segunda cena da sequência, é o amanhecer do dia seguinte, em que Maud tenta se aproximar de Jean-Louis e ele se esquiva. 
Como costumava afirmar em suas entrevistas (HANDYSIDE, 2013), Éric Rohmer tinha como marca de filmagem quase não repetir as tomadas, procedimento que propiciava maior economia de filme (HERPE, 2007). A duração dos planos e o trabalho com as vozes em off é reflexo dessa escolha. A partir do segundo momento da primeira cena, a variação de perspectiva das vozes parece ser mais controlada, mesmo envolvendo a presença de três atores conversando, o que diz muito sobre o trabalho do operador do boom, no caso, o técnico Alain Sempé, assistente de Ruh, ainda em início de carreira. O próprio Ruh comenta sobre esse tipo de situação:

É como um trabalho de pintura que é feito, em geral, pelo meu colaborador, o operador de boom [perchman]. Por exemplo, nós três estamos aqui conversando e cada um de nós possui uma cor de voz diferente. Suponha que uma câmera nos enquadre, eu um pouco fora de quadro, você completamente de frente e o outro um pouco de lado. Aqui nós temos uma espécie de verdade sonora para encontrar do ponto de vista de captação mesmo. O que significa em dar para minha voz um nível específico, a você um nível de voz em pleno quadro e para o terceiro um outro tipo de voz. Existe uma localização ideal a encontrar, é um trabalho de pintura feito com movimentos bem leves em função dos deslocamentos de cada um. É um trabalho muito delicado, muito corporal, que se faz em conjunto com o operador de som. (SAADA; OSTRIA, 1988, p. 85, tradução nossa)

Ao fazer farto uso das vozes em off, ao mesmo tempo em que propicia uma economia de planos, o trabalho de câmera passa a valorizar mais as expressões de reação e os olhares. No caso da cena do apartamento de Maud, essa valorização será ainda mais fundamental ao possibilitar explorar as reações e olhares de Maud, em relação principalmente às revelações pessoais de Jean-Louis, dando maior destaque à atuação de Françoise Fabian. Um dos planos que evidencia bem isso é o que mostra Maud, já deitada em sua cama, pedindo um copo d’água para Jean-Louis, que está fora de quadro. Ao invés da decupagem mostrar a ação de Jean-Louis indo buscar a água para depois entregar à Maud, a câmera fica em Maud, que está em silêncio, deixando Jean-Louis falando fora de quadro. Percebemos toda a sua ação pelos sons em off do deslocamento até a garrafa d'água e do copo d'água sendo enchido para só depois Jean-Louis retornar em quadro, entregando o copo para Maud.

Curiosamente, o filme contém apenas uma cena dublada: a cena final, que se passa em uma praia em que Jean-Louis, sua esposa Françoise e seu filho pequeno encontram Maud. De acordo com Jean-Pierre Ruh, Rohmer filmou essa cena um 
ano antes na Ilha de $R^{10}$ com uma pequena câmera e sem som (HERPE, 2007). Nessa cena, percebe-se uma descrição do espaço pelo som totalmente oposta ao resto do filme. As vozes dos atores permanecem sempre no mesmo plano de volume e o som ambiente, formado por ruídos de vozes e pássaros ${ }^{11}$, soa como se saíssem de um ambiente mais confinado, abafado, o que contrasta com o que a imagem apresenta, a praia e o mar em sua amplitude. $\mathrm{O}$ aspecto de confinamento das vozes vem a ser característico em filmes que optam pela dublagem, caros à escola italiana e japonesa de som, por exemplo. Ao se manterem inalteradas, em uma perspectiva fixa, as vozes perdem a mobilidade dentro do espaço e sua ressonância, mesmo que em alguns casos se perceba um trabalho feito em pós-produção que busque disfarçar a origem da voz deslocada do espaço cênico da filmagem. Voltaremos a falar desse assunto mais adiante.

\section{Le genou de Claire}

Em seguida a Ma nuit chez Maud, Jean-Pierre Ruh realiza com Rohmer Le genou de Claire (O joelho de Claire, 1970), feito com um melhor aporte financeiro graças ao sucesso de Ma nuit chez Maud, o que dará a Rohmer condições bem mais favoráveis de filmagem (BAECQUE, HERPE, 2016). Le genou de Claire adota um respeito radical ao som direto obtido em situação de filmagem. "Não existe uma só palavra que tenha sido pós-sincronizada, mesmo em certas sequências em que descobri que podíamos ouvir muito o vento nas folhas dos choupos - mas que Rohmer queria manter", diz Ruh (HERPE, 2007). Por meio do tratamento dado ao som, percebemos a abertura de uma janela para o mundo que aproxima o discurso ficcional de uma experiência documental.

Le genou de Claire narra a história de Jerome, que, às vésperas de seu casamento com Lucinde, passa alguns dias em sua casa de veraneio, situada às margens do lago de Annecy, na França. Lá ele encontra Aurora, escritora e antiga amiga, que está hospedada na casa de Madame Walter, mãe da adolescente Laura e da jovem Claire. Estimulado por Aurora, que passa a utilizá-lo como cobaia para um exercício ficcional, Jerome se envolve com Laura e Claire, cujo joelho acaba

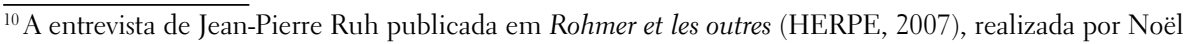
Herpe e Priska Morrissey, deixa em dúvida qual seria a única cena dublada no filme. Jean-Pierre Ruh pergunta para os entrevistadores se eles saberiam dizer qual seria a cena dublada, os entrevistadores respondem se não seria a cena de Trintignant e Marie-Christine Barrault nas montanhas de Clermont. Na resposta transcrita de Jean-Pierre Ruh, não consta a informação correta, como se ele corroborasse com os entrevistadores. No entanto, pela descrição que faz, fica nítido que ele está se referindo à cena final do filme.

${ }^{11}$ São passarinhos alegres e insistentes muito semelhantes àqueles que ouvimos no filme anterior de Rohmer, La collectionneuse (A colecionadora, 1967).
} 
por obcecá-lo. Mais uma vez temos um filme centrado na voz e na palavra, com a predominância de cenas de conversas, caras a Rohmer.

Ao contrário de Ma nuit chez Maud, Le genou de Claire tem por característica ser um filme em que os ruídos e as ambiências se sobressaem. Isso se deve ao fato de boa parte das cenas terem sido filmadas em ambientes externos. A harmonia entre os planos de som, comentada em relação à Ma nuit chez Maud, é menos presente. Temos vários momentos em que o corte dos planos de imagem e som são deixados à mostra em sua descontinuidade no que se refere aos sons de fundo, às ambiências. Em comparação a Ma nuit chez Maud, em Le genou de Claire a exploração das vozes em off é menor. Em geral, nas cenas filmadas nos jardins externos às residências, vemos duas pessoas conversando sentadas em um banco, o que favorece uma posição frontal das duas em relação à câmera, bem como o enquadramento em conjunto. Uma cena que quebra essa disposição frontal é a cena que se passa na sala de Madame Walter, em que vemos quatro pessoas (a própria Madame Walter, seu vizinho Jacques, Jerome e Laura) sentadas em quatro pontos da sala, sendo que Madame Walter está sentada no mesmo sofá que Jacques. A cena é curta e sua decupagem é marcada por planos próximos, em que a disposição de todos no espaço é dada somente pela relação estabelecida pelos olhares. Apenas no momento em que Laura deixa a sala é que podemos ver a real disposição dos atores em um mesmo plano de conjunto. Nessa cena, temos o uso mais recorrente das vozes em off e da variação de perspectiva dessas vozes na relação com o espaço.

A abertura para o mundo dada pela captação em som direto marca momentos curiosos no filme, como a entrada de sons de carros e motos, que passam em off, em contraste com a ambientação bucólica dos jardins das casas de veraneio que vemos na imagem. Jean-Pierre Ruh comenta sobre isso:

Existia uma bela reverberação natural dentro deste ambiente em forma cuia, cercado por montanhas; mas isso significava também uma armadilha: nos momentos de muito tráfego, a gente escutava como se os carros estivessem próximos quando na verdade estavam do outro lado do lago, a seis ou sete quilômetros de distância... (HERPE, 2007, tradução nossa)

Além do barulho dos carros, ouvimos também o sino de uma igreja, que em nenhum momento aparece no filme, em duas cenas que se passam no mesmo lugar, o jardim da casa de Jerome. Na primeira, Jerome conversa com a jovem Laura, ambos sentados em um banco. No segundo momento, Jerome está com a escritora e amiga Aurora, também no mesmo jardim, sentados no mesmo banco. O sino entra 
pontuando rigorosamente uma fala de Aurora, que comenta sobre suas recentes experiências afetivas, em uma feliz obra do acaso.

Essa abertura de uma janela para o mundo por meio do som, dada pelo microfone, possui especial interesse quando analisamos a maneira como a encenação é construída. Em relação ao quadro imagem, o que temos é um evento totalmente controlado, apoiado no trabalho dos atores que encenam as cenas do roteiro em um local do mundo, o ambiente bucólico do entorno do lago de Annecy. Em Le genou de Claire, esse evento quase sempre envolve um grupo pequeno de pessoas dispostas em um ambiente que favorece o controle em relação a tudo aquilo que seria estranho a esse mundo ficcional, como o tráfego de pessoas e carros ao redor, típicos dos ambientes urbanos. Mais ainda, o trabalho de câmera reforça esse aspecto de controle a partir do rigor estabelecido por quadros fixos obtidos pelo uso da câmera em tripé. Ao optar pela captação em som direto, o controle dos eventos estranhos à diegese em relação ao som já não é mais possível. Lembrando Jonathan Sterne, o quadro imagem possui relação direcional com seu objeto, oferecendo uma relação em perspectiva, já o som possui uma relação esférica com seu entorno, oferecendo uma relação de submersão (STERNE, 2003). Nesse sentido, é possível controlar a relação em perspectiva dada pelo recorte estabelecido no quadro da imagem. Já a relação de submersão no mundo dada pelo som, não. Como disse Jean-Pierre Ruh, o tráfego dos carros podia estar bastante distante do evento a ser filmado, mas em função das características do ambiente geográfico, entrou como algo bastante presente na cena a partir dessa brecha para o mundo aberta pelo microfone. As intervenções desses eventos sonoros não controlados pela mise-en-scene é uma das características quando se trabalha com som direto, sendo muitas vezes incorporada pelo filme. Uma situação semelhante foi vivida por Antoine Bonfanti no filme De man die zijn haar kort liet knippen (O homem com a cabeça raspada, 1966) de André Delvaux. Trata-se da sequência que mostra uma autópsia e que ocorre em um ambiente externo, próxima a uma igreja. Diz Bonfanti: "No último plano, tocou o sino da igreja. E o Delvaux esperou. Podia ter dito 'Corta!' pelo menos sete ou oito segundos antes. Mas esperou pelo fim da ressonância do sino para dizer.” (Pimentel; Vasconcelos, 1985, p. 20-21).

Voltando a Le genou de Claire, o clímax sonoro fica reservado para o final, coincidindo com o clímax dramático do filme, a sequência em que Jerome e Claire são obrigados a se abrigar sob uma espécie de gazebo para se protegerem da chuva. Esse é o momento em que Jerome acaricia o joelho de Claire, após revelar a ela um suposto affaire do namorado de Claire com outra mulher. Como lembra Jean-Pierre Ruh: 
Era uma chuva artificial, feita com uma mangueira de bombeiro: portanto, à medida em que nós lançávamos os jatos d'água, a chuva se acumulava e o barulho ficava mais e mais forte; eu fui forçado a fazer calhas para drenar a água e tentar manter o mesmo fundo... Aquilo não era tomada de som, era jardinagem digna de uma brigada de incêndio! Quanto aos barulhos de trovões, eu gravei depois. (HERPE, 2007, tradução nossa)

A chuva entra como um intenso ruído de fundo. O respeito ao som direto é marcado pela grande variação desses ruídos de fundo entre os planos que formam a decupagem em campo e contracampo da cena, variação perceptível mesmo com todo o trabalho de Ruh, descrito acima, na preparação da tomada. Toda a cena é decupada em vinte planos. No primeiro momento da cena, do plano um ao plano doze, Jerome está de pé, diante de Claire, que está sentada em um banco de madeira. Após questionar Claire sobre o paradeiro do namorado, Jerome pega um banco e se senta próximo a Claire. No plano seguinte, Jerome diz a ela que viu o namorado com outra garota, provocando o choro de Claire. Um plano fechado em Jerome prepara o plano seguinte, em que Jerome finalmente acaricia o joelho de Claire, no décimo sexto plano da cena. Dos vinte planos, apenas na transição entre o décimo sexto e o décimo sétimo é que percebemos uma relação contínua e harmônica do ruído de fundo, em todas as demais trocas de planos a continuidade não é de todo mantida, apesar dos esforços de Ruh comentados anteriormente.

Ressaltar aspectos relacionados à variação dos sons de fundo na montagem das cenas, não significa dizer que os planos de som foram mantidos no corte final em suas versões brutas sem qualquer tipo de tratamento de pós-produção. Ao contrário, as tomadas feitas em ambientes externos com todos os ruídos de carros, sinos, vento e folhagens, conforme comentados por Ruh anteriormente, exigiram bastante do trabalho de mixagem. Como explica o técnico:

[...] de todos os diretores com quem trabalhei, Rohmer é o único que reiniciou uma mixagem porque eu não estava satisfeito com o resultado. Em Le genou de Claire, nós mudamos o editor, o mixador e o próprio estúdio de som, nós fizemos a transferência da película. Em primeiro lugar porque o produtor Pierre Cottrell queria, e porque Rohmer me deu razão. De fato, melhoramos a qualidade do som em $40 \%$, cuja primeira versão era bem ruim - embora tenha sido mixada por Jacques Maumont. Tudo isso feito em harmonia, sem conflitos. Pode acontecer que o aparato técnico seja mais ou menos adequado, que o técnico de mixagem esteja mais ou menos preparado, que se relacione melhor ou pior com o diretor. De fato, como todos os filmes que fiz com 
Rohmer, eu estava envolvido na mixagem - não a praticando, mas estando lá para dar instruções. (HERPE, 2007)

Uma das funções do técnico de som direto, além de atuar na captação de sons durante a filmagem, é justamente coletar material sonoro, fora do horário de filmagem, como ambiências e ruídos, que servirá de base durante o processo de mixagem para eventuais ajustes das transições e possíveis acréscimos de informações sonoras que sirvam à narrativa, como no caso do barulho dos trovões, na cena de Claire e Jerome, que informam a chegada da chuva. Todos esses são sons cuja origem se encontra nesse local de mundo escolhido para as filmagens e não em meras bibliotecas de sons. Conforme comentado por Baecque e Herpe (2016), em Le genou de Claire, muito do trabalho de Ruh se deu na captação dos sons ambientes, principalmente no que diz respeito ao canto dos pássaros, sons que guardam estreita relação não apenas com o local geográfico da filmagem, mas também com a época do ano em que ocorreu a filmagem, o que voltará a ser discutido.

\section{L'amour l'après-midi}

Dois anos após Le genou de Claire, Jean-Pierre Ruh faz seu terceiro filme com Rohmer, L'amour l'après-midi (Um amor à tarde, 1972). O longa narra a história de Frédéric (interpretado por Bernard Verley), um homem casado e com boa estabilidade profissional, que reencontra uma antiga amiga, Chloé (interpretada pela atriz Zouzou). Os encontros entre os dois passam a ser frequentes, ocorrendo sempre nos períodos da tarde, até ao ponto em que Frederic se vê na iminência de trair sua esposa Hélène (interpretada por Françoise Verley, que na vida real era também esposa do ator).

Ao contrário de Le genou de Claire, em L'amour l'après-midi trocamos o ambiente bucólico dos arredores do lago de Annecy pelo ambiente urbano de Paris. Boa parte do filme irá se passar em interiores de escritórios, cafés e apartamentos. Mais uma vez, o uso do som fora de campo (off) aparece em destaque, dando base para a construção de uma mise-en-scene totalmente apoiada no som. Ao contrário do que vemos em Le genou de Claire, em L'amour l'après-midi o som não ficará restrito aos sons diegéticos obtidos em tomadas sincrônicas. A voz extradiegética de Fréderic ocupa considerável espaço na trilha sonora, atuando como elemento condutor da narrativa. Assim como em Ma nuit chez Maud, temos também uma sequência dublada, a sequência do sonho de Fréderic, em que as vozes entram de forma bastante limpa e deslocada com o que vemos na imagem. 
A palavra e a voz novamente são elementos centrais em L'amour l'après-midi, com destaque especial para a voz da atriz Zouzou. Eric Rohmer sempre foi bastante atento às peculiaridades da voz, não apenas como veículo para uma expressão semântica clara e funcional para questões relativas ao texto do roteiro, mas também naquilo que seriam suas características físicas, sua sonoridade. Diz ele: "Eu dou muita importância à fala, ao estilo, à qualidade da voz e sua entonação.” Em outra entrevista: "Eu encorajo esse tipo de modulação de voz, o uso de inflicções diferentes." Ou ainda: "É o lado musical dos meus filmes; porque, como você sabe, eu nunca uso música. A única música nos meus filmes é a música das vozes das pessoas" (HANDYSIDE, 2013, p. 20, tradução nossa). Sobre a importância dada por Rohmer ao som, Ruh comenta:

Acontecia às vezes do Nestor Almendros lhe dizer, em uma segunda tomada: 'A panorâmica no final do plano não estava de toda perfeita’; Rohmer me perguntava então qual era a melhor tomada e eu lhe respondia: 'Na segunda tomada aconteceu qualquer coisa interessante a nível da entonação, as vibrações do timbre. Por mim soou muito bem nos ouvidos.' E em geral Rohmer escolhia a tomada mais interessante no que concerne ao plano sonoro. (SAADA; OSTRIA, p. 84, tradução nossa)

Ao pensar a captação da voz, Jean-Pierre Ruh estava lidando também com uma série de elementos a ela ligados, relacionados à boca e ao próprio físico dos atores. "O que eu amo é o sopro, a respiração dos atores. Isso vem muito da minha experiência com reportagens, mas também de meus trabalhos com Eustache e Rohmer", diz Ruh (SAADA; OSTRIA, 1988, p. 85, tradução nossa). Aspectos diretamente ligados ao trabalho da boca, como a salivação e lubrificação, também podem interferir na emissão da voz, dando uma característica bastante particular à fala e ao estilo da atuação. Em L'amour l'après-midi, vamos encontrar na atriz Zouzou um excelente exemplo desses aspectos periféricos do som da voz, caros à concepção de som de Jean-Pierre Ruh.

Jean-Pierre Ruh costumava classificar os tipos de vozes dos atores em dois, aqueles que possuíam uma voz de "tórax", mais grave, e aqueles que possuíam uma voz de "garganta", mais aguda. Para as vozes de tórax, Ruh tinha por princípio captar com dois microfones, um por baixo e outro por cima. Os atores de garganta, Ruh preferia captar por meio de microfone de lapela, que Ruh passaria a usar com mais frequência a partir do filme Perceval le gallois, de 1978 (HERPE, 2007). Para Ruh, "cada ator possui sua aventura sonora” (SAADA; OSTRIA, 1988, p. 84). Em L'amour l'après-midi, Jean-Pierre Ruh comenta que teve dificuldades na captação 
da voz da atriz Zouzou. Diz ele: "Eu me recordo que tive problemas com Zouzou, que era magnífica, mas que tinha uma voz bem complicada para captar, um pouco branca, não muito marcada" (HERPE, 2007, tradução nossa). Zouzou possui uma voz grave e fechada, o que dificulta a captação, principalmente quando é feita com microfones direcionais aéreos, além do fato de que o francês é uma língua muito apoiada em vogais fechadas. A voz de Zouzou, no entanto, exemplifica bem algo caro a Jean-Pierre Ruh na sua concepção de som direto, no que diz respeito não apenas à captação das vozes, com seus timbres, frequências e volumes, mas também aos sons produzidos pela boca durante a elocução verbal. Estamos falando de sons relacionados àquelas imperfeições da fala, como a respiração e a salivação. São sons que, para Jean-Pierre Ruh, acrescentariam um valor de verdade à tomada, algo que ele sempre valorizou em suas entrevistas (ENTRETIEN.., 2012; SON..., 1988) e que, para ele, era impossível de se obter em estúdio. Embora sejam sons menores, ordinários, que passam quase despercebidos ao ouvido comum, eles sempre cativaram o trabalho de escuta de Jean-Pierre Ruh. Os ruídos de respiração e salivação reforçam a ancoragem da voz com o corpo de quem a emite com toda a sua singularidade.

As falas da atriz Zouzou são frequentemente acompanhadas por um trabalho de lubrificação da boca, com o uso da língua para umedecer os lábios entre uma elocução e outra, o que é bem percebido nos planos mais próximos da atriz. Uma das cenas que exemplifica bem essa característica vem a ser uma que se passa no interior do escritório de Frédéric. Chloé, a personagem de Zouzou, aparece após um período de ausência. Os dois conversam rapidamente. Chloé informa que conseguiu um emprego como garçonete em um restaurante. Frédéric diz que sentiu falta da amiga. O plano de interesse é um plano próximo em Chloé, o último dos três planos que marcam a decupagem da cena. Frédéric fica fora de campo e se movimenta pelo escritório. O movimento de Frédéric é acompanhado pelo olhar de Chloé. Sentimos toda a movimentação de Frédéric também pela variação de volume de sua voz. A voz de Chloé permanece em primeiro plano, enquanto a de Frédéric fica de fundo, dada a proximidade do microfone em Chloé, enquadrada em um plano fechado. Os sons de sua salivação são bastante sutis, porém perceptíveis pela forma como tenta lubrificar sua boca com a língua. Aqui podemos citar como referência o livro de Brandon LaBelle (2014), Lexicon of the Mouth: Poetics and Politics of Voice and the Oral Imaginary, em que temos um minucioso levantamento dos sons possíveis de serem produzidos pela boca e que nem sempre levamos em consideração quando estudamos a voz. Entre os vários tópicos abordados, vamos encontrar o verbete lubrificação, em que LaBelle aborda esses pequenos sons bem exemplificados pela 
sequência de L'amour l'après-midi. Diz LaBelle: “Toda essa materialidade úmida suporta os desempenhos necessários do eu, enquanto ele fala e exprime, vocaliza e anima, come e expele" (2014, p. 41)

\section{Considerações finais}

Conforme costumava comentar em entrevistas (ENTRETIEN..., 2012; SON..., 1988), Jean-Pierre Ruh tinha como método de trabalho utilizar sempre o mesmo suporte de captação, no caso o Nagra III. Com relação aos microfones, Ruh utilizava os de lapela, porém tendo sempre o microfone aéreo como principal. A variação da escolha dos microfones dependia das condições de filmagem. Os longas Ma nuit chez Maud e Le genou de Claire foram filmados em épocas do ano com climas bastante diferentes, um no inverno e outro no verão. Segundo detalha Ruh em uma longa entrevista dada para o projeto Imagem e Memória, depositada na Biblioteca Nacional da França (BNF) ${ }^{12}$, para Le genou de Claire, ele optou por aqueles que chamava de microfones mais agressivos, que propiciavam a captação de sons mais agudos, ideais para captação das ambiências, do canto dos pássaros, diferentemente dos que foram adotados para Ma nuit chez Maud (ENTRETIEN..., 2012). Essas escolhas serão determinantes para o tratamento final do som do filme. Entre os três filmes analisados, percebe-se uma diferença na maneira como eles soam. Dos ambientes mais silenciosos de Ma nuit chez Maud aos ambientes mais ruidosos de Le genou de Claire, passando pelos ruídos urbanos de Paris em L'amour l'après-midi. Cada filme possui uma particularidade própria, assim como um som único, que não se repete, mesmo com todas aquelas imperfeições a que nos referimos anteriormente, uma questão cara a toda a escola de som direto. Em comum, os três exploram, via captação de som direto, as vozes sempre projetadas no espaço, quer sejam espaços fechados ou abertos. Isso acrescenta uma informação de perspectiva e profundidade. São vozes captadas em situação de mundo, que carregam as características físicas dos atores em sua relação direta com o entorno, dos corpos no espaço.

Essa característica da voz no espaço, com toda a dimensão física do corpo que a emite dentro desses espaços de mundo, que encontramos nos três filmes analisados aqui, não está presente no primeiro filme da série Contos Morais, em função não apenas da adoção da dublagem, mas de como essa dublagem é trabalhada no tratamento sonoro do filme. Trata-se do curta-metragem de vinte e três minutos La boulangère de Monceau

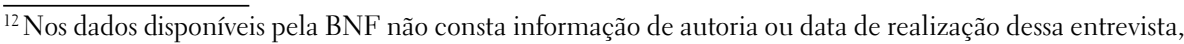
uma longa entrevista de quatro horas de duração, captada em quatro fitas mini DV. Agradeço à Priska Morrissey pelas informações complementares disponibilizadas na relação filmográfica desse artigo. (ver: https://bit.ly/3f9A3eA)
} 
(A padeira de Monceau, 1963), de Éric Rohmer. Feito em condições amadoras em $16 \mathrm{~mm}$, o filme é conduzido pela voz do narrador e personagem interpretado por Barbet Schroeder ${ }^{13}$, que ocupa o espaço fora de campo. As vozes dos personagens em situação dialógica entram sem que se perceba nenhuma distinção de espaço entre as vozes diegéticas dos personagens e a voz extradiegética do narrador fora de campo, mesmo no caso em que vemos os personagens nos ambientes externos das ruas de Paris, informados pela imagem e pela inserção dos ruídos de tráfego dos automóveis, locais em que se passam a maior parte das cenas. É como se todas as vozes fossem emitidas dentro de um mesmo espaço, um espaço neutro, não os espaços de mundo. Esse aspecto também se percebe nas cenas externas de La carrière de Suzanne (A carreira de Suzanne, 1963), um média-metragem de cinquenta e quatro minutos, o segundo filme da série. Mantendo o mesmo procedimento do filme anterior, o média-metragem é conduzido pela voz fora de campo do personagem Bertrand. Ao contrário de La boulangère de Monceau, em La carrière de Suzanne predominam as cenas internas, principalmente de apartamentos. Segundo Baecque e Herpe (2016), nesse filme Rohmer contou com a participação do crítico e cineasta Jean-Louis Comolli (não creditado) que captou precariamente o som com um microfone de ambiente ligado a um gravador. O uso do som pós-sincronizado se mantém no terceiro filme a ser produzido, o quarto da série, o longa-metragem La collectionneuse (A colecionadora, 1967). A qualidade do trabalho de pós é visivelmente mais apurada, visto que o filme contou com melhores recursos financeiros, sendo dessa vez filmado em $35 \mathrm{~mm}$. Esses três primeiros filmes da série contaram com o trabalho (também não creditado) de Jackie Raynal ${ }^{14}$ na montagem do som e mixagem (BAECQUE; HERPE, 2016).

Após L'amour l'après-midi, Jean-Pierre Ruh fará ainda mais dois filmes com Rohmer, Die Marquise von O... (A Marquesa d'O, 1976) e Perceval le gallois (Perceval, o Gales, 1978), filmes que marcam a entrada de Rohmer no campo dos chamados filmes históricos e que mantêm a exploração do som direto, porém em condições favoráveis ao trabalho de Ruh (Die Marquise von O... foi quase todo filmado em ambientes internos e Perceval le gallois foi filmado em estúdio). Entre os anos 1970 e 1980 Jean-Pierre Ruh será nome constante nos créditos de filmes como os de Antonioni, Win Wenders, Polanski, Resnais e, sobretudo, Marco Ferreri. Ao final de sua vida, JeanPierre Ruh trabalhará intensamente em produções voltadas para a televisão, vindo a falecer em 2006, no mesmo ano de falecimento de Antoine Bonfanti, seu grande mestre.

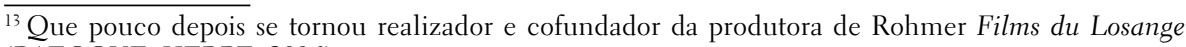
(BAECQUE; HERPE, 2016).

${ }^{14}$ Cineasta que mais tarde se associará ao grupo Zanzibar, de Philippe Garrel.
} 


\section{Referências}

ALVIM, L. B. A. M. "Performances musicais em filmes de Rohmer, Truffaut e Godard dos anos 60”. In: OPOLSKI, D.; BELTRÃO, F. B.; CARREIRO, R. (org.). Estilo e som no audiovisual. São Paulo: Socine, 2018. p. 160-181.

BAECQUE, A.; HERPE, N. Éric Rohmer: a biography. New York: Columbia University Press, 2016.

BARNIER, M. “Les premiers ingénieurs du son français”. 1895: Mille huit cent quatre-vingt-quinze, Paris, n. 65, p. 200-217, 2011.

BRESCHAND, J.; MORRISSEY, P. “Pour saluer Jean-Pierre Ruh, extrait d'un entretien avec un grand homme du son”. Cahiers du Cinéma, Paris, n. 615, p. 62-63, 2006.

BRISSON, D. “Un homme mûr du son: Jean-Pierre Ruh (entretien)”. Ciné Critiques Films, Paris, n. 27, p. 26-27, 1984.

CHION, M. A audiovisão: som e imagem no cinema. Lisboa: Texto \& Grafia, 2011.

GARCIA, A. R. Contos morais e o cinema de Éric Rohmer. Curitiba: Arte e Letra, 2019.

HANDYSIDE, F. (ed.). Eric Rohmer: interviews. Jackson: University Press of Mississippi, 2013.

HERPE, N. (org.). Rohmer et les autres. Rennes: Presses Universitaires de Rennes, 2007. Disponível em: <http://books.openedition.org/pur/633>. ISBN: 9782753526891. DOI: https://doi.org/10.4000/books.pur.633.

LABELLE, B. Lexicon of the mouth: poetics and politics of voice and the oral imaginary. London: Bloomsbury, 2014.

MARIE, M. "Quebec - França, voltas, reviravoltas, vaivéns nas duas direções". Rebeca, São Paulo, v. 2, n. 2, p. 86-109, 2013.

Pimentel, V.; Vasconcelos, A. "Encontro com Antoine Bonfanti". In: Pimentel, V.; Vasconcelos, A. Antoine Bonfanti: homenagem a um técnico de som. Lisboa: Cinemateca Portuguesa, 1985. p. 11-35.

PUCCINI, S. “A escola francesa de som direto: Antoine Bonfanti e Paul Vecchiali, o caso Femmes, femmes (1974)”. Aniki, Lisboa, v. 7, n. 1, p. 23-40, 2020.

PUCCINI, S. “Antoine Bonfanti e a escuta do mundo em documentários não controlados". Doc On-line, Lisboa, n. 22, p. 95-105, 2017. 
SAADA, N.; OSTRIA, V. "A l'ecoute du jeu, entretien Jean-Pierre Ruh". Cahiers du Cinéma, Paris, n. 407-408, p. 83, 1988.

SEGURA, J.; MOURIÈS, C. "La grande aventure du cinema c'est le son". Les Nouveaux Dossiers de L'audiovisual INA, Paris, n. 3, p. 41-42, 2005.

SOUZA, J. B. G. Procedimentos de trabalho na captação de som direto nos longasmetragens brasileiros Contra todos e Antônia: a técnica e o espaço criativo. 2010. Tese (Doutorado) - Universidade de São Paulo, São Paulo, 2010.

STERNE, J. The audible past: cultural origins of sound reprodution. Durham: Duke University Press, 2003.

TAKAMI, M. C. Comentários sobre o som na obra de Éric Rohmer. In: Encontro Socine, 16., 2012, São Paulo. Anais [...]. São Paulo: Socine, 2013. p. 354-361.

\section{Referências filmográficas}

SIX contes moraux I: La boulangère de Monceau (A Padeira do bairro). Éric Rohmer, França, 1962.

SIX contes moraux II: La carrière de Suzanne (A Carreira de Suzanne). Éric Rohmer, França, 1963.

SIX contes moraux , III: Ma nuit chez Maud (Minha noite com ela). Éric Rohmer, França, 1969.

SIX contes moraux, IV: La collectionneuse (A colecionadora). Éric Rohmer, França, 1967.

SIX contes moraux, V: Le genou de Claire (O joelho de Claire). Éric Rohmer, França, 1970.

SIX contes moraux, VI: L’amour l'après-midi (Um amor à tarde). Éric Rohmer, França, 1972.

\section{Referências audiovisuais}

ENTRETIEN avec Jean-Pierre Ruh. Paris: CNRS Images, 2012. 4 mini DV (4h): 4/3, cor (PAL).

SON et cinema: le son direct. Paris: France Culture, Radio France, 1988.

submetido em: 13 ago. 2021 | aprovado em: 1 nov. 2021 